\title{
City-County Health Department Mergers
}

\author{
A. JAMES THOMAS, M.S.P.H., M.S.A., and R. L. PETERSON, B.A.
}

On the basis of published accounts of previous consolidations, this paper outlines the questions posed and summarizes alternative courses of action. It is presented, with appreciation of its limitation, in anticipation of additional reports of field studies of consolidation experiences.

GOME 180 city-county health department $\mathcal{N}$ consolidations have been effected in the United States. Judging by inquiries received by the Public Health Service from local officials, civic groups, and private citizens regarding the pros and cons of consolidation, it seems likely that many more such mergers will take place. Each community, of course, must devise plans to fit its own individual circumstances, but many of the questions to be answered are common to all mergers. The experience gained in previous consolidations may therefore prove helpful to other communities considering such action.

\section{Why Consolidate?}

Advocates of city-county consolidation of health services advance a variety of benefits. Some claim that economy and efficiency are the primary underlying motives. Mergers generally cannot be justified on the basis of a reduction in expenditures, but a case can be

Mr. Thomas is assistant chief, Planning and Evaluation Branch, Division of Health Mobilization, Public Health Service, and Mr. Peterson is executive officer, Arctic Health Research Center, Public Health Service. At the time this paper was written, both were public health advisers, Division of Community Health Practice, Public Health Service. made for increased efficiency and more effective use of personnel, especially critical professional staff. For example, the Davidson CountyNashville, Tenn., consolidation led to shifts in personnel, which resulted in better services at lower costs, but the number of public health problems needing intensified effort precluded any reduction in expenditures. For a few years, however, the consolidated health department did increase services without increasing expenditures $(1 a)$

Commenting on 10 city-county consolidations in Michigan, Fryer (2) pointed out that "the motivation to merge usually is the desire to make more efficient use of the available money and the available trained public health personnel. Both frequently are in short supply and inefficient use of these resources is, to an extent, usually unavoidable when two health agencies perform the same function and offer the same services in a community. City taxpayers in dual-department communities often complain (and justifiably so) that they are forced to pay taxes for the support of two health departments when they need but one. Providing countywide health services through funds raised countywide has come to be recognized as the most equitable way to furnish these services."

The significance of the drive for efficiency and economy, however, may well be overemphasized. The impetus for merger often seems to be more a concern for the adequacy of health services than for their costs. In the Jefferson CountyLouisville, Ky., and the Knox County-Knoxville, Tenn., consolidations, the elimination of duplication was coupled with an expansion of services and increased expenditures ( $(3)$.

Expansion or even assimilation of all existing 
services is not an inherent feature of consolidation, of course. Although an expansion of services to unincorporated areas was contemplated by the consolidation of the city and county health departments in Sacramento, Calif., several functions of the former city health department were not transferred to the new organization: plumbing inspection, the dog pound, and the emergency hospital, for example. These are now operated separately by the city $(4 a)$.

Some States offer financial inducements to encourage broader, more stable bases for local health operations. During the 1930's New York State contributed 50 percent of the operating cost to counties which consolidated their health departments (5). More recently, Pennsylvania has established a system which gives counties that consolidate their health departments a matching grant equal to 50 percent of all approved expenditures up to a ceiling limit of 75 cents per capita $(6)$.

Financial considerations may, however, bear adversely on merger. In Texas and other States where cities receive no State aid and the property tax is relied upon heavily, cities are in a poor position to extend health or any other services to the mushrooming suburbs. The suburban communities in these States, on the other hand, have little or no incentive to consolidate in the absence of "accidental windfalls" such as Tennessee cities receive from division of sales tax revenue ( $y)$.

Other specific arguments in support of consolidation include the following:

1. A single department with the flexibility necessary to meet major emergencies.

2. Greater correlation between scope of health problems and extent of administrative responsibility for handling them.

3. A higher and more consistent level of services throughout a given geographic area.

4. A central point for reporting diseases and requesting laboratory services.

5. Broader, unified tax base to finance desired programs and a given level of services.

6. Uniform regulations, fees, and licenses.

7. Uniform personnel policies and the possibility of attracting better personnel through higher salaries and greater opportunities for advancement.

When the question of health department con- solidation is presented separately from proposals for broader governmental adjustments, these considerations are often sufficient to lead a community to accept merger. Opposition, however, frequently arises. One commonly expressed fear is that the level of service to the more highly developed urban community will be reduced, or that the prospect for improved services will be diminished in order to achieve first a common level of services for the entire area. Such fears cannot always be dismissed as groundless, especially when the level of services is obviously lower in one jurisdiction than in the other. Perhaps more often, however, the real issue is fear of higher taxes to finance extension, expansion, and improvement of services.

The organization of health services may not be, and perhaps cannot be, considered separately from other governmental adjustments in metropolitan areas. Therefore, health department consolidation sometimes is opposed because of its possible implications for more far-reaching adjustments or because it conflicts with the pattern of intergovernmental relationships already developing. Jurisdictional jealousies, the result of an unfavorable political and intergovernmental climate, may present an unsurmountable roadblock to a desired and needed consolidation.

\section{How To Consolidate?}

No merger action is possible unless it is authorized by State statute. Generally, however, legal authority for cooperative action exists in some form, although there may be referendums or other procedural hurdles to surmount.

Transfers of activities from one local government to another may facilitate consolidation. In Nashville, Tenn., the Davidson County Health Department assumed several specific functions, rabies control, for example, from the city before the consolidation $(1 b)$. On the other hand, some authorities contend that "ad hoc" transfers of specific activities tend to delay rather than encourage consolidation.

Transfers of functions may be based on special legislative acts or on general permissive legislation. Functional transfers usually proceed from the mutual consent of governments con- 
cerned, but some States require a specific form of local government to assume a function transferred from a second form $(8 a)$.

The development of permissive legislation in California illustrates what can be done to facilitate intergovernmental adjustments. County home rule was established there by constitutional amendment in 1911. Subsequent amendments permitted charter counties to perform municipal functions under contract. A 1921 law authorizing functional transfers was both preceded and followed by legislation on specific types of functional transfers. Finally, in 1953, a method was provided for interested people to pay for intensified services in unincorporated areas. County governing bodies were authorized to establish areas in which a special local tax could be levied to finance extended services supplied by the county $(8 b)$.

Direct action by the voters to establish consolidated districts is usually possible, but not highly probable. Most governmental reorganization proposals submitted to the electorate are rejected. Fears of higher taxes or reduced services undoubtedly have a strong effect on voting behavior. Nevertheless, there are some successes. Proposals for county charter governments generally include provisions for a county health department with powers formerly assigned to cities and towns. Dade County, Fla., for example, obtained a home-rule charter and enumerated certain transfers of powers concerning health $(8 c)$.

Direct action by local officials is a method more frequently employed. Under enabling legislation adopted in 1952, the county commissioners of Allegheny County, Pa., acted by resolution to consolidate the Pittsburgh and Allegheny Health Departments into an Allegheny County Health Department (9). In Eau Claire, Wis., the county and city boards of health were abolished in 1941 by joint action of the two jurisdictions. A seven-member, nonpolitical board was established, with four members appointed by the mayor and three by the county board chairman (10).

Thus, where State laws are favorable, the legal aspects of merger are easily developed and implemented. The situation in Michigan as described by the director of local health services is illustrative ( $\mathscr{2})$ :
"Michigan's public health laws provided that a county health department has jurisdiction throughout the entire county, except in cities having an organized health department with a full-time health officer. If the city charter permits, the city health department can be abolished by resolution or ordinance by the city's governing body. This action automatically places the city under the jurisdiction of the county health department. If the charter does not permit abolishment in this way, the city can name the county health officer to serve concurrently as city health officer."

Appointment of the same health officer to head more than one health department is often a first step toward consolidation. In all seven of the Michigan communities where mergers fall short of complete consolidation (2), a medical director serves as the administrative head of both city and county health departments. All seven, however, are working toward consolidation.

Another device is to leave city health officer vacancies unfilled on the assumption that the county will assume responsibility for extending health services to the cities. The cities of Oakland and Alameda, Calif., followed this course. Subsequently, Alameda County responded to a petition to provide countywide health services.

Provision of health services through contracts is being increasingly used to achieve what in effect amounts to consolidation. As a rule, where this means is employed, the county sells services to a city or town. The usual procedure for initiating a contract is for the city to submit a proposal to the county. Following approval by the governing body of the county, a finding by the State health department relative to the organization and capabilities of the county health department may be required. The contracting city usually dissolves its board of health and ceases to operate a health department of its own. Contractual arrangements, like independent authorities, are open to the criticism that the consuming public has little or no way to make itself heard in regard to broad policy formulation.

In most mergers of local health departments, the county assumes responsibility. The boundaries of counties are more likely to approximate the limits of metropolitan areas than are the boundaries of other local units. In many areas, public education and health and welfare 
services are traditionally provided by counties. As emphasized in a recent study, North Carolina counties generally finance and assume responsibility for those services needed by everyone throughout the county without regard for location or density of population (11). Many counties have gradually abandoned the role of rural administrative agent of the State government in favor of a new role as a metropolitan government providing a wide array of services in unincorporated areas. Piecemeal transfers of individual functions from other local governments to counties have given great impetus to the advocacy of metropolitan health departments. Another factor has been State legislation designed to encourage consolidation. It may be easier to convert counties to metropolitan governments than to create new general governments of metropolitan jurisdiction. Other metropolitan approaches frequently have been rejected or have proved inadequate when they became operative.

Cities have assumed responsibility for metropolitan areas, but not frequently. Only two general governmental consolidations in the 20 th century have placed all activities under city administration: Baton Rouge, La., in 1917 and Hampton, Va., in 1952. Consolidations during the previous century included New Orleans, New York, Philadelphia, and Boston (8d).

Despite the historical pattern, cities may provide a stronger base for health operations than counties. Cities, for example, may be in a better position to provide necessary physical facilities because of their superior borrowing powers. Also, cities are more likely to have functioning merit systems. City assumption of responsibility for health services throughout a county could be the most feasible approach if the city occupies the major portion of the county and the remainder is unincorporated suburbs or a few small incorporated places, assuming, of course, the political and intergovernmental climate is favorable.

Although final responsibility for operations usually rests with one jurisdiction, joint assumptions of responsibility do occur. The Pueblo, Colo., City-County Health Department is an example. Such an arrangement permits municipal-type services in the city and more limited services in the county, particularly when the county outside the city is predominantly rural.

The forms which consolidation take vary widely in specific detail, but they may be classified broadly as shown in the following list. These alternatives were suggested by a professional study group in a 1957 survey of the Cleveland metropolitan area $(12 a)$.

Combined health district. Cities and county consolidate permanently through a contract providing that one of the existing boards becomes the administrative body for the combined jurisdictions. The contract specifies the cost to the cities and to the county.

Cooperative independent health districts. A method of achieving program coordination rather than an organizational form, this arrangement is often the first step toward consolidation. All the boards of health in the district contract with the same health commissioner to serve as top administrator, but each board continues to pay its own expenses.

Contract for services. By an annual contract a county or city sells specific services to smaller cities within the metropolitan area. This mechanism is governed by State statutes and health codes. It has been especially useful in metropolitan areas where numerous small cities contract with a county to provide health services.

County or metropolitan federation by charter. A metropolitan health department may be developed by popular vote for a county charter government, if the State constitution permits. Special authorization might provide for the election of a local charter commission. A charter establishing the new health department could then be drafted for the voters' approval.

County health district. Approval by the electorate of a resolution authorizing the county commissioners to appoint a county board of health is a direct approach where State legislation permits.

Union health district. This is another approach which does not assume a broader governmental consolidation. The difference between this method and the establishment of a county health district is that here the decision to combine is taken by the elected officials, such as county commissioners, mayors, and district council. Special State legislation is often required to permit this action. 


\section{How To Finance?}

Many of the factors which determine the organizational form and placement of the new unit also influence its financial support.

County health departments receive financial support from such sources as:

1. Tax funds, traditionally derived from taxes on real estate.

2. Licensing fees, usually placed in the general health fund for use in support of any activity.

3. Contracts, specifying the cost of specific services or establishing a fixed basis for sharing costs of joint operations.

4. Voluntary agency grants, usually in the form of subsidization of specific personnel by tuberculosis, cancer, or heart associations.

5. State assistance, usually flat amounts for health departments which meet minimum requirements but also payments for specific personnel, supplies, or equipment. Increased amounts may be provided as an incentive for increased local expenditures.

6. Special levies for public health activities, where State law permits. The decision to place a special levy before the voters is a major policy issue for a department. The chance of not obtaining desired funds is often balanced against the increased attention the special levy will bring to the department's need for support.

Financing of city health departments usually is less complex. The city council appropriates the necessary funds for the city's operating funds. Fees and other revenue usually go into the same general fund.

Each of these sources of revenue has implications in planning consolidated health operations. For example, the consultants to the Cleveland metropolitan study group in 1957 recommended that legislation to create a combined department include a tax levy for financing it (12b). Voluntary organizations may be willing to provide special personnel in order to demonstrate their usefulness to the community. Personnel and budget adjustments may be made to meet the requirements for State assistance. Establishment of a uniform schedule of license fees is an administrative necessity.

The most important financial consideration is the question of who should pay for services.
A view expressed in Dade County, Fla., was that "each governmental level should be responsible for its own financial affairs, but the county should be in charge of assessment and property tax collection for all" (13). The following conclusions of a 1939 survey of the financing of city-county consolidations are still worthy of consideration (14):

"If the area selected includes only the territory already urban, or even if ... it includes a margin which later proves insufficient, the problem, the solution of which is sought, simply arises on a new frontier, with stronger obstacles and enhanced jealousies to overcome.

"If the area selected includes an ample margin for all possible growth, much of it must remain rural pending that growth; and then, as a practical matter, either the rural territory must be relieved of some portion of the taxes charged against the urban territory . . . or else if it pays the full taxes, the consolidated government must try to give it all the services which other taxpayers receive ... an attempt which proves financially difficult or - ruinous."

Opponents, it was stated, fail to note "the practical difficulties in securing city-county consolidation without some tax differential. . ..."

Those contemplating consolidation must determine whether tax differentials are desirable and whether they are legal. In States where the county taxes incorporated areas, tax differentials already exist. This situation, however, is generally viewed by city officials and residents as dual taxation. Land use largely determines the types of local services needed. "Residential areas require both services to property ... and services to persons. . . . Commercial and industrial areas need special services to property but require fewer services to persons. Finally, agricultural and undeveloped land in urban areas requires few or no direct services to either persons or property (15)."

Proposals for financing consolidated health departments have varied widely. Arizona proposed varying tax rates on the basis of many factors, including the number and types of services given (16). Pueblo, Colo., considered a system of tax zones so that rural areas would not be taxed for municipal services (17). For Harris County and Houston, Tex., two tax zones were proposed, one for the urban area and another for the nonurban area (18). A general 
services tax district and an urban services district were proposed for Nashville-Davidson County, Tenn. (19). For Sacramento, Calif., three service areas were proposed, a metropolitan services area with a uniform tax sufficient to finance minimum areawide services, such as courts and jails, health and welfare, roads, and mosquito control; an urban service area composed of those portions of the county having an urban population and urban land uses and constituting a special assessment district for the additional taxes necessary to finance many of the required municipal services; and user charges to be paid by the consumers for such services as water, sewerage, garbage collection, and transit (20).

Written agreements between city and county governments permitting the formation of a combined health department should provide a basis for financing the department. To fail to do this is to risk dissolution of the combined department, a prospect which faced the Pueblo City-County Health Department in its first 4 years. A satisfactory formula for joint financing finally was developed whereby each jurisdiction is in essence paying for the services it receives $(\mathscr{2} 1)$.

The governing bodies involved in a merger should also draw up a written agreement on the budget. One jurisdiction often assumes final responsibility for the budget, but not always, particularly in the transitional period before consolidation is completed.

A major consideration in preparing the new budget is the provision of adequate funds to meet the costs of merger. In Sacramento, Calif., the county made a large capital outlay to complete and equip a new health center. In the next fiscal year the city and county jointly contributed $\$ 160,000$ to the county budget for the cost of consolidating the two departments $(4 b)$.

As has been pointed out $(12 c)$, "It is important to separate the cost of combining from the cost of improvements and from the inflationary cost which may be introduced through such factors as adjustments in salaries." Where new facilities are needed, assistance may be available from the Hill-Burton program. These improvements, as well as additional staff, are probably less costly than the same improvements by several independent jurisdictions. Elimination of nonproductive effort, savings in expenditures and staff time from uniform administrative practices, and hand tailoring of professional services to local needs suggest savings which may greatly reduce the cost of added services.

The fiscal advantages of merging health services within the context of a larger governmental consolidation were demonstrated in Dade County, where operational planning and performance budgeting techniques are being used, and a thorough administrative analysis was made of departmental operations. In spite of expansion in several areas, including health and welfare programs, it was possible to reduce the property tax rate. In addition, more idle funds were placed in interest-bearing deposits, borrowing became easier, and bond issues enjoyed remarkably favorable interest rates (2R).

\section{Personnel and Staffing Problems}

The merger of city and county health departments generally poses a number of personnel problems. Though none are unique, some take on added significance within the framework of consolidation.

Merit system coverage. In some States all local health departments operate on a statewide merit system. Under such circumstances, no problem exists. More frequently, however, local departments are under their city or county merit systems, or they have none at all. The virtues of the merit principle aside, a merit system is desirable because it is usually a prerequisite to receipt of State or Federal grant funds.

In some situations it has proved advantageous to adopt the State merit system, in effect, by contracting with the State civil service or personnel agency for services. If one of the merging departments was already operating under a merit system and the other was not, usually the existing system is extended to the combined department. In the Nashville-Davidson County, Tenn., merger, however, the combined departments contracted with the State for merit system services rather than adopting Nashville's civil service plan. Legal and other 
expert assistance generally is required to provide the information needed for a sound decision on how merit system coverage may best be achieved. The publications "Merit System Installation" (23) and "Whither the Merit System?" (24) are helpful guides on this subject.

Classification plan. A position-classification plan is an essential part of any merit system or sound personnel program. If either of the merging departments is operating under a merit system with a classification plan, this plan may be adopted by the new department. If no classification plan exists, an inventory of all positions, covering kind and difficulty of work and specific duties and responsibilities, needs to be made. On the basis of this inventory, classes and class titles can be tentatively established, positions allocated, and class specifications prepared. Each employee should be notified immediately in writing of the class and grade to which his position has been allocated and of the procedures to follow should he wish to appeal.

Pay plan. A parallel pay plan may be adopted along with an existing classification plan. In establishing a new salary schedule, the following factors need to be considered:

1. Prevailing pay rate for public health workers in the State, area, and jurisdictions of comparable size.

2. Fringe benefits, including leave, pension plan, and health insurance.

3. Financial condition of the jurisdiction.

4. Promotional opportunities.

5. Equitable relationship among various position grades as to difficulty of work, degree of responsibility, and educational and experience requirements.

The change from one pay scale to another generally calls for adjustments in employees' salaries. For employees whose old salaries were lower than the new minimum for their present classification, salaries are generally raised to the new minimum. Employees whose old salaries were above the new maximum for their positions present the only real problem. One solution is to freeze their salaries at the old level with no increases other than those earned by promotion.

Retirement and fringe benefits. Iueave earn- ings are usually preserved and the employees' balances carried forward even though the new leave system differs somewhat from that of either merging unit. Retirement plans often pose a knotty problem. As Fryer indicated (2), "Perhaps the most difficult problem that arises during merger negotiations is that of withdrawing employees from the city retirement system and transferring them to the county retirement system. For employees with long city service, a transfer can work a financial hardship but usually some equitable arrangement can be worked out." Actuarial help may be needed to insure that employee retirement benefits are preserved and that the consolidated system is sound and adequate.

Retention and recruitment. Efforts to retain the staff employed by the merging units are important, especially in view of the scarcity of professional health personnel. Such efforts not only promote good will but may result in sizable savings in the recruitment and training of new employees. Although most employees can continue in the same type of work, it occasionally is necessary to give a few temporary jobs until comparable ones are set up, or to provide retraining.

Performance, experience, and education of retained employees are important in determining which of them are eligible for promotion. But, while opportunities for promotion should be provided for employees who are qualified to undertake greater responsibilities, experience of consolidated departments indicates the need for sufficient flexibility to recruit qualified individuals outside the department.

Employee morale. Deterioration of employee morale can be minimized during the period of consolidation if employees are kept informed of all developments. It is especially important that employees be notified as soon as possible that:

1. No pay reductions will occur.

2. Every effort will be made to place them in similar jobs.

3. There will be some choice of work location, if the consolidated department is to operate district health centers.

4. There will be an apparatus for appealing job classification actions.

5. Fringe benefits will be preserved. 
Early establishment of classification and pay plans alleviates fears of any monetary loss.

\section{Summary and Conclusions}

Several questions are common to all health department mergers: the desirability of such action, the form the merger should take, the level of services, and how to finance and staff the new department.

These questions have been answered in numerous past consolidations, but no fixed pattern has emerged. The solutions have differed to meet the circumstances of specific community situations. But examination of past mergers does offer some guidelines. What is needed now is more extensive and intensive study to sharpen the view of the determinative factors. A few case studies would also be valuable in revealing additional aspects of consolidation.

As urbanization and suburbanization increase, there will be more and more pressure to find new ways of providing community services, and it seems likely that consolidation will be considered often. It is important, therefore, that the advantages and disadvantages of consolidation, as demonstrated in practice, become more widely known.

\section{REFERENCES}

(1) Community Services Commission: A future for Nashville. Nashville, 1952, (a) pp. 151-164; (b) p. 66.

(2) Fryer, D. H.: Ten cities-counties merge health functions. Mich. Municipal Rev., February 1959, pp. 37-39.

(3) Nat. Municipal Rev. 32: 628, December 1943.

(4) The government of metropolitan Sacramento. Public Administration Service, Chicago, 1957, (a) p. 180 ; (b) pp. 179-180.
(5) Freeman, A. W.: A survey of health organization and service: Columbia County, New York. State Charities Aid Association, New York, 1931.

(6) The county health department. Educational and Scientific Trust of the Medical Society of the State of Pennsylvania, Harrisburg, Pa., 1957.

(7) Greene, G. S., and Grant, D. R.: Metropolis: Texas style. Nat. Municipal Rev. 46: 571-572, December 1957.

(8) Council of State Governments: The States and the metropolitan problem. Chicago, 1956, (a) p. 105 ; (b) pp. 112-113; (c) pp. $89-91$; $(d)$ 54-56.

(9) Nat. Municipal Rev. 45: 450-451, October 1956.

(10) Nat. Municipal Rev. 31: 462, September 1942.

(11) Esser, G. H.: Greensboro suburban analysis. Institute of Government, Chapel Hill, N.C., 1956, p. 66 .

(12) Cleveland Metropolitan Services Commission, Study Group on Public Health: Public health in greater Cleveland. Cleveland, Ohio, Nov. 15, 1957, (a) p. 23; (b) p. 167; (c) p. 150.

(13) Greater Miami gets chance to pioneer home rule. Business Week, Nov. 17, 1956, pp. 176-178.

(14) Chubb, L. R.: The financial aspects of citycounty consolidation. Nat. Municipal Rev. 28 : 101-104, February 1939.

(15) Tollenaar, K. C.: Taxation differentials. Nat. Municipal Rev. 48: 118-122, March 1959.

(16) Public Management 39: 237, October 1957.

(17) Nat. Municipal Rev. 38: 142-143, March 1949.

(18) Public Management 40: 68, March 1958.

(19) Nat. Municipal Rev. 45 : 550-552, December 1956.

(20) Nat. Municipal Rev. 46: 362-364, July 1957.

(21) Sidio, A. D., and Anderson, J. S.: Budgeting a combined health department. Pub. Health Rep. 73 : 582-584, July 1958.

(22) Campbell, O. W.: Metro Dade County, Florida: first annual report. Miami, 1959, pp. 12-13.

(23) Merit system installation. Public Administration Service, Chicago, 1941.

(24) Whither the merit system? National Civil Service League, New York, 1945, p. 4.

\section{Peace Corps Recruits}

Requests for Peace Corps volunteers, from the Ivory Coast, Ethiopia, Somali, Togo, Tunisia, Honduras, Jamaica, and North Borneo, include applications for health educators, public health nurses, teachers, and social workers. Other projects are shaping up in Bolivia, Peru, and Venezuela. Inquiries may be directed to the Peace Corps, Washington 25, D.C. 